\title{
IMPROVING THE DESIGN OF INTERPERSONAL SKILLS MODULES FOR IT/MIS CURRICULA: FINDINGS FROM A CORPUS LINGUISTIC RESEARCH
}

\author{
Constanta-Nicoleta Bodea, The Bucharest University of Economic Studies, bodea@ase.ro
}

\begin{abstract}
The development of graduate interpersonal skills is considered as an important outcome of IT and MIS educational programmes, in order to assure the graduate employability and their professional success. The aim of this paper is to presents the results of a corpus-based analysis on 103 syllabi of interpersonal skills courses and trainings, in order to discover patterns of the content structuring and trends in teaching and assessment methods. The research findings allow the author to make recommendations for the improvement of the design of the interpersonal skills courses included in the IT/MIS curricula.
\end{abstract}

Keywords: Interpersonal skills, IT/MIS curriculum, corpus linguistics.

\section{INTRODUCTION}

The connection between higher education institutions and labor market is usually defined in terms of the responsibility of higher institutions to enhance graduate employability. In the literature, various key interpersonal skills are listed as being directly connected to employability (Pinto \& Ramalheira, 2017; Popescu \& Roman, 2018, Beaumont et al., 2016). In the 1980s, the attention was given to the generic or "transferable" skills, letting people to succeed in a wide range of different jobs and tasks (Training Agency, 1990). In our days, the focus is shifting to the transversal skills or to the so-called "21st century skills", such as: communication, team working, critical thinking, problem solving, leadership or managerial abilities. But employability goes beyond the simplistic notion of the key skills; it is related to a mix of personal qualities and beliefs, knowledge, as well as practical experience..

Teaching and learning interpersonal skills are considered as being challenging tasks (Bodea, 2018). Some of the reasons are listed below:

- It is not an agreement on how to identify the relevant interpersonal skills set for a specific domain/profession.

- Interpersonal skills are portable, in the sense that they are valuable to any domain/profession. So, what is a good approach for teaching/learning interpersonal skills: to use a specific professional context or a more generic/general one?

- Interpersonal skills have a psychological foundation that asks for an interdisciplinary approach when we teach or learn them.

- Interpersonal skills are interrelated. For example, we cannot teach/learn conflict management without teaching/learning effective communication and negotiation. Designing the content of the course based on all these interdependencies is not possible, considering the time limit imposed by the curriculum.

- There are many different teaching methods, which are usually applied to develop the interpersonal skills. Almost all of these methods are practice-based. Organizing and performing these activities take long time and experienced professors/trainers are needed.

- There are not clear rules for assessing the mastering of interpersonal skills, making the assessment difficult.

Interpersonal skills are considered as being very important in IT, not only for employability but also for the professional success. Different international curricula in IT include several modules or disciplines for interpersonal skill development. The development of graduate interpersonal skills is considered as an important outcome of the international curricula in informatics

a) ACM and IEEE Curriculum in Computer Engineering for Undergraduate Degree Programmes (https://www.acm.org/binaries/content/assets/education/ce2016-final-report.pdf). The curriculum report was released in 2016 and presents the expected graduates knowledge and skills for the computer engineering 


\section{Issues in Information Systems}

Volume 21, Issue 4, pp. 178-186, 2020

undergraduate programmes (ACM-IEEE, 2016a). The starting point in developing this curriculum was the body of knowledge (BoK) and the input from industrial and educational institutions. BoK describes the broad knowledge areas (KAs) with a thematic scope and a set of knowledge units (KUs), with associated learning outcomes. The curriculum report emphasizes on the requirements for including professional practice and courses related to legal issues and interpersonal skills, such as: oral and written communication and teamwork. The development of these skills can be achieved by the means of practicum, internship and cooperation programs with companies, mainly organized as extracurricular activities and by the means of team-based Implementation of technical-oriented courses. The report includes sample curricula referential models, which universities might select and used for developing their own curricula, considering also specific student goals and local/regional characteristics.

b) ACM and IEEE Information Technology Curricula for Baccalaureate Degree Programs. (https://www.acm.org/binaries/content/assets/education/curricula-recommendations/it2017.pdf). It is a curricular framework for worldwide baccalaureate IT programs preparing graduates to work with current and future IT technologies. It was released at the end of 2017 and reflects the specificity of information technology in comparison with other computing disciplines. It incorporates results from previous curricular products, defined by ACM and IEEE. In addition, many faculty and employer surveys were conducted, in order to estimate the global trends of information technology, as an academic discipline and economic sector, as well. A competence-based and student-centered approach was adopted. The working definition for IT competence is "what students know (content knowledge), how they demonstrate performance (skills), and how disposed they are to apply what they know, in IT professional contexts (the personal qualities/attitudes)". Information Technology Curricular framework includes Communication skills and Teamwork and Conflict management skills into the essential IT domain ITE-GPP Global Professional Practice, together with other skills, such as: project management, risk identification and environmental issues. This essential domain covers only $3 \%$ of the curriculum scope. The recommended solution for enhancing the students' communication skills is to include some course on mechanisms of writing, presentation delivery and presentation critiques. Team work and Conflict management skills can be enhance by working in projects during their study. The solutions offered by IT Curriculum can't lead to a significant improvement of graduate interpersonal skills, as they are required on the labor market.

c) ACM and AIS Global Competency Model for Graduate Degree Programs in Information Systems (https://www.acm.org/binaries/content/assets/education/msis2016.pdf). The model of competences was firstly introduced in 1972 and its latest version was released in 2016. The graduate competencies represent the starting point in the curriculum development work. Until 2016, the main focus in curricular design was to define the prerequisites, to identify the competence areas, by targeting different job profiles and to decide which competences are the core ones. After 2016, the curriculum design meant the implementation of competence model in the specific local labor markets. The structural component of the global competence model is the graduate competence, defined as knowledge, skills (abilities of using knowledge), and attitudes to successfully perform a task (Topi et al, 2010). There are three main competence areas, refined in several competence categories. These three areas are: Information Systems Competencies, Individual Foundational Competencies, and Domain Competencies. The Individual Foundational Competencies area includes the following competence categories: critical thinking, creativity, ethical Analysis, oral and written communication, problem solving, collaboration and teamwork, leadership and negotiation. It is considered that the development of these interpersonal skills is achieved by means of the research methods course, the course on academic writing and the capstone project.

\section{RESEARCH METHODOLOGY}

The research objective was the identification of teaching and learning solutions for the interpersonal skills development modules/disciplines. The selected research method was corpus linguistics applied for a more than 100 syllabi of interpersonal skills courses and trainings, in order to discover patterns of the content structuring and trends in teaching and assessment methods. Courses and trainings in interpersonal skills were identified based on Internet searches. The selection criteria for the corpora inclusion were the following:

- Recently delivered courses and trainings (delivered in the latest years)

- Content and methods for teaching and assessment well described in the syllabus

- Diversity of course and training organizers 
- Selected geographic area: English speaking countries, mainly from North America (USA and Canada), but also UK and Australia

In total, 103 courses and trainings have been selected: 50 courses and trainings in Conflict and Crises Management, 33 courses in Interpersonal skills and 20 trainings in Interpersonal skills. The course/training content part of the syllabi were extracted and organized in .txt files. Methods part of the syllabi were also extracted and organized in separate .txt files. In total, 206 .txt files were created and analyzed with the AntConc software.

Corpus linguistic (or corpus-based analysis) represents a computer-aided exploration of textual data (corpus/corpora), representing real examples/instances of language in use. The main application domain of this type of analysis is the linguistics. Corpus linguistics represents the study of language, as expressed in real word texts. Corpus-based analysis and corpus linguistics are usually considered as being interchangeable. In fact, we consider that term corpus-based analysis extend the applicability of this analysis methodology to other domains than linguistics (Muresan, 2017; Anthony, 2004). Corpus-based analysis is applied in the study of grammatical patterns, in speech analysis/speech synthesize, in sociolinguistics, for discourse analysis, in lexicography, stylistics, semantics, etc. The main characteristics of corpus-based analysis are:

- It is an empirical analysis, based on instances of authentic language

- It requires a large quantity of textual data, electronically stored and processed

- It requires a specialized software

- It uses both quantitative and qualitative analysis techniques, such as frequencies of occurrence/ co-occurrence of different linguistic elements or patterns, qualitative interpretation of the concordances or sequences of words

Some of the relevant techniques applied in the corpus-based analysis are concordancing, word frequency counting and categorizing. Concordancing implies viewing words in their contexts, similar with the Keyword in Context (KWIC). The concordance plots show the distribution of words in the analyzed text. Counting the word frequency is a common technique, very often used in corpora analysis. There are common also the analysis implying identification of clusters with a specific word or of identification of all "n-grams" with a specific size.

AntConc software was released in 2002, as KWIC (Key Word in Context) concordancer program, for the classroom usage. During the years, the software has evolved into a freeware, multi-platform, multi-purpose corpus analysis toolkit (Anthony, 2005). It has a friendly and intuitive graphical user interface. ActConc platform includes the following tools: Concordancer tool, Concordance Search Term Plot Tool, View Files Tool, Word List Tools, Keyword List Tools and Word Clusters /Bundles Tool. Concordancer tool is the central platform component, facilitating the learning of vocabulary, collocations, grammar and writing styles. The most common features of Concordancer tool are directly accessible on the main screen. Concordance Search Term Plot Tool has a similar functionality as Concordancer Tool in terms of search options. Only the results visualization is different. There are boxes, representing files. Multiple lines representing relative positions of the search terms there are plotted in each box. View Files Tool is used to display the search term in the original file. Word List / Keyword List Tools generate lists of terms/key words, which can be sorted into alphabetical or frequency order. A list of high frequency functional words can be specified in order to avoid calculations for these terms. A list of only the words that should be considered for frequency calculation can be also defined. The Word Clusters / Bundles Tool is used for analyzing multi-word units, such as collocations, phrasal verbs and idioms. Bundles are similar with n-grams, composed by two until five words

The research was conducted in order to answer to the following guiding questions:

(1) How courses focusing on specific interpersonal skills (for example, Conflict and Crisis Management) extend their scope, in order to address other interpersonal skills, which are interrelated with the main one?

(2) What is the scope, in terms of skills covered by courses with a broad declared subject (for example, Interpersonal skills)? Which are the most common interpersonal skills addressed under the umbrella of "interpersonal skills" in courses?

(3) What is the scope, in terms of skills covered by trainings with a broad declared subject (for example, Interpersonal skills)? Which are the most common interpersonal skills addressed under the umbrella of "interpersonal skills" in trainings?

(4) Are there significant scope differences between courses and trainings with a broad declared subject?

(5) Which are the most commonly applied teaching and assessment methods applied in courses with a broad declared subject? 
(6) Which are the most commonly used teaching and assessment methods applied in trainings with a broad declared subject?

(7) How much practical-orientation characterizes the teaching and assessment methods applied in courses with a broad declared subject?

(8) How much practical-orientation characterizes the teaching and assessment methods applied in trainings with a broad declared subject?

(9) Are there significant differences on the practical-orientation of the applied teaching and assessment methods between courses and trainings with a broad declared subject?

(10) Are there significant differences in teaching and assessment methods between courses with a broad coverage and those with specific focus, as courses in Conflict and Crisis Management?

\section{RESEARCH RESULTS}

The following answers to the guiding questions were obtained by applying corpus linguistic:

(1) For answering to the question "How courses focusing on specific interpersonal skills (for example, Conflict and Crisis Management) extend their scope, in order to address other interpersonal skills, which are interrelated with the main one?”, the word list tool was used. The following interpersonal skills are frequently associated with the conflict and crisis management: negotiation/negotiations/negotiating (78 times), communication (30 times), team work (12 times), emotion management (11 times) and self-management (10 times).

(2) In order to answer to the question: "What is the scope, in terms of the skills covered by courses with a broad declared subject? Which are the most common interpersonal skills addressed under the umbrella of interpersonal skills in courses?", the word list tool was also used, as it is showed in figure 1.

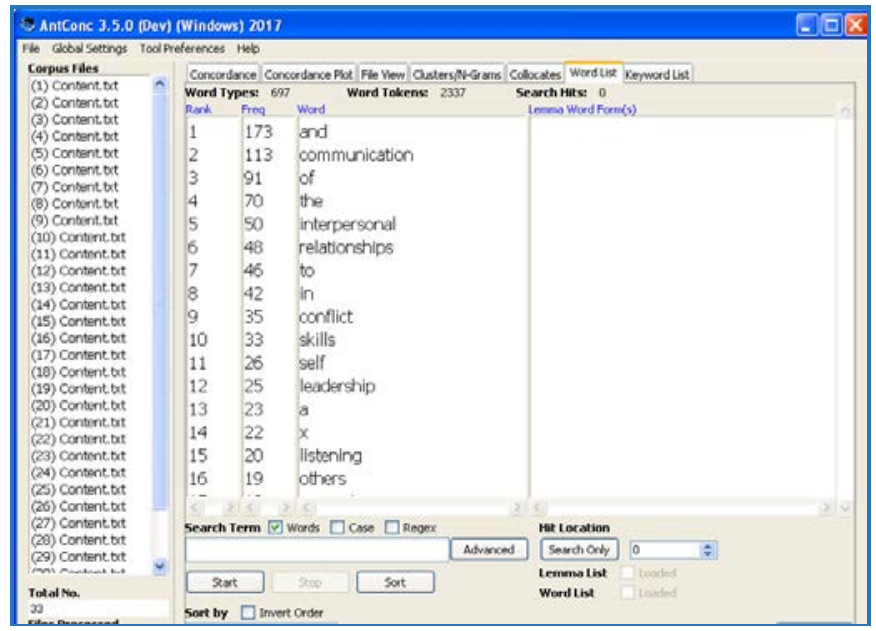

Figure 1. The word list tool usage for analyzing the content of Interpersonal skills courses

The following interpersonal skills are frequently covered by courses with a broad declared subject: communication (113 times), relationship management (48 times), conflict (35 times), self-management (26), leadership (25 times), emotion management (22 times) and listening (20 times).

(3) The question: "What is the scope, in terms of skills covered by trainings with a broad declared subject (for example, Interpersonal skills)? Which are the most common interpersonal skills addressed under the umbrella of interpersonal skills in trainings?” was answered by using also the word list tool. The following interpersonal skills are frequently covered by trainings with a broad declared subject: communication/communicating (84 times), listening (25 times), influencing others (17 times) and relationship management (13 times).

(4) The answer to the question: "Are there significant scope differences between courses and trainings with a broad declared subject?” is: Yes, there are significant differences in the scope between courses and trainings with a broad 


\section{Issues in Information Systems \\ Volume 21, Issue 4, pp. 178-186, 2020}

declared subject. Trainings have a more limited scope than courses. Considering the skills covered under the umbrella term "interpersonal skills", communication is, by far, the most frequent skill associated with interpersonal skills. Relationship management and conflict management are also considered as relevant interpersonal skills, in courses and trainings.

(5) The answer to the question "Which are the most commonly applied teaching and assessment methods applied in courses with a broad declared subject?" is: The most commonly used teaching methods are: group activities, class presentations and reflection sessions. Regarding the assessment methods the participation at class activities, especially at group activities represents a common requirement and a criterion for assessing the courses participants (see figure 2). The answer was identified by using the Concordancer tool.

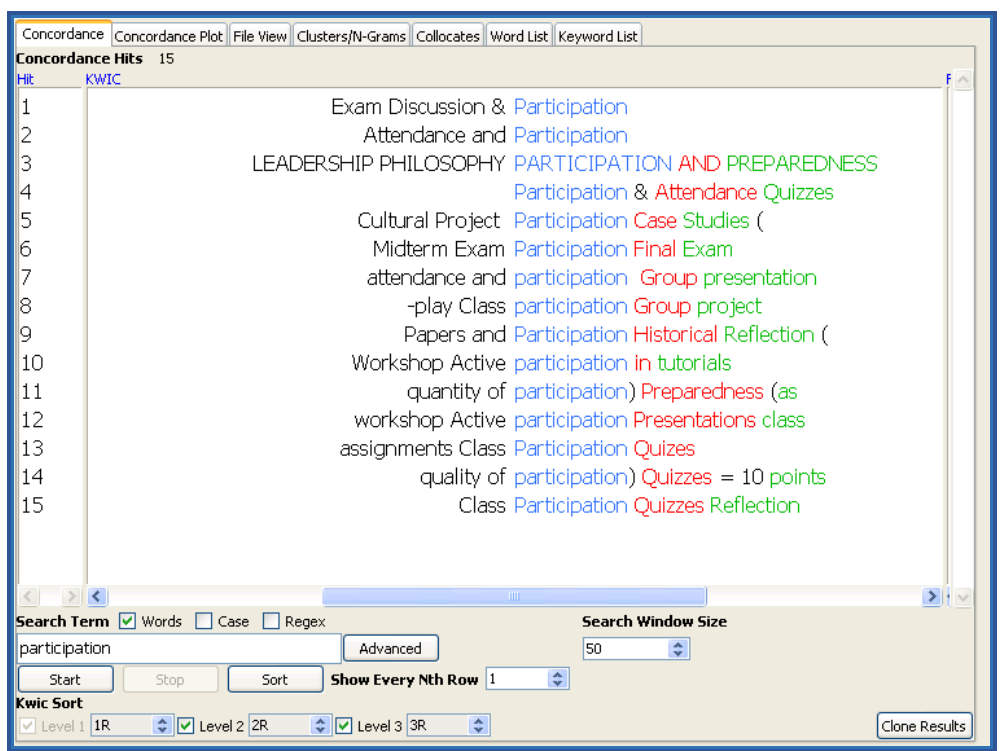

Figure 2. Participation, the most common assessment criterion in courses with a broad declared subject

(6) The answer to the question: "Which are the most commonly applied teaching and assessment methods applied in trainings with a broad declared subject?" is the following: The most commonly used teaching methods in trainings are the workshops, small group activities and facilitated individual tasks. The exercises are the most common assessment method in trainings (see figure 3).

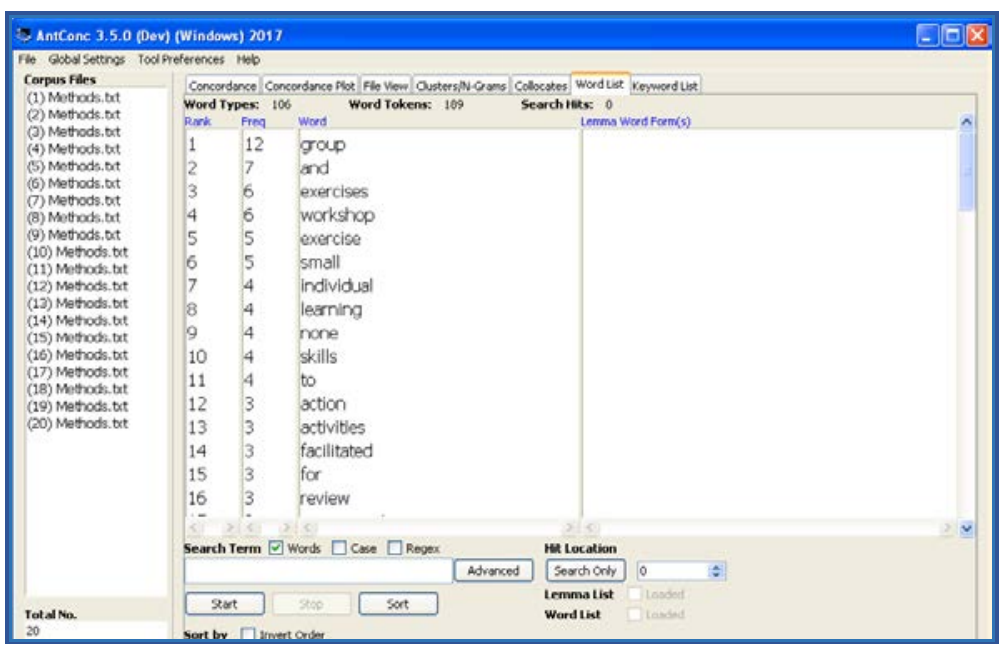

Figure 3. Teaching and assessment methods in trainings with a broad declared subject 
The group activities have different forms in trainings, as can be seen in figure 4 . These results were obtained by using the Concordancer tool.

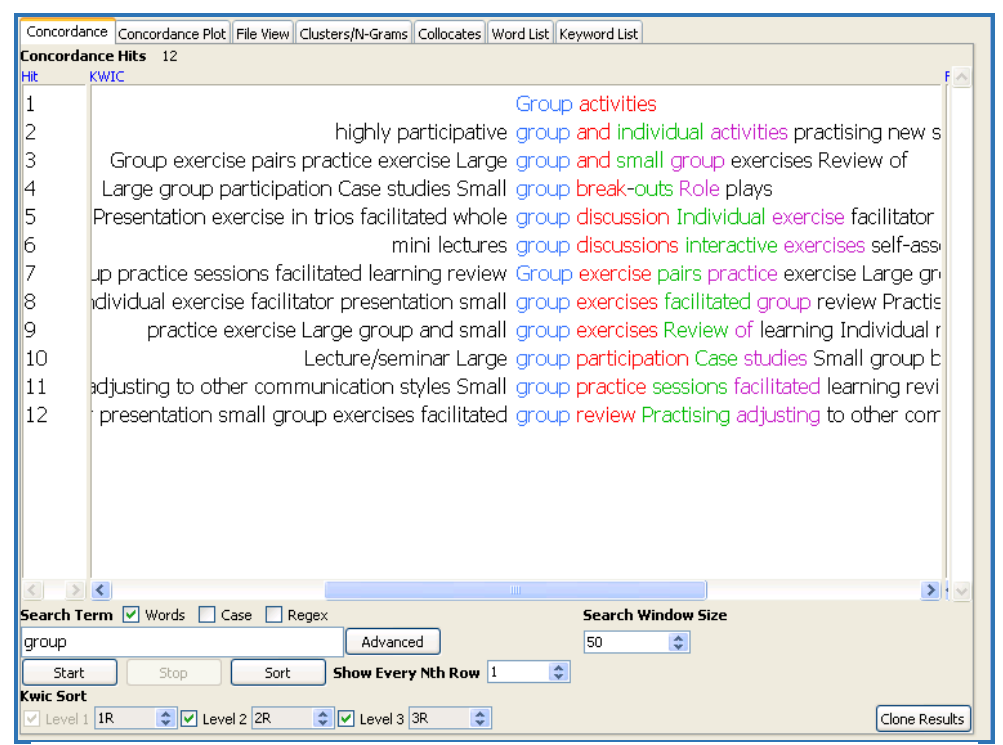

Figure 4. Group activities in trainings with a broad declared subject

(7) The answer to the question: "How much practical-orientation characterizes the teaching and assessment methods applied in courses with a broad declared subject?" is The teaching methods assure the practical orientation of courses, but usually, practice is not explicitly declared.

(8) Regarding the question: "How much practical-orientation characterizes the teaching and assessment methods applied in trainings with a broad declared subject?", it is not common to explicitly declare practice sessions in trainings. In the analyzed corpus, only six time the practice/practical/practicing words appeared.

(9) Yes, there are significant differences in the practical-orientation of the applied teaching and assessment methods between courses and trainings with a broad declared subject. Trainings are more practically oriented than courses, due to the frequent usage of workshops and other group activities.

(10) Yes, there are significant differences in teaching and assessment methods between courses and trainings with a broad coverage and those with specific focus, as courses in Conflict and Crisis Management? In the courses and trainings focused on specific interpersonal skills, practice is more often explicitly declared as a teaching method Also, the group activities are more diverse (see figure 5 and 6 ). 


\section{Issues in Information Systems}

Volume 21, Issue 4, pp. 178-186, 2020

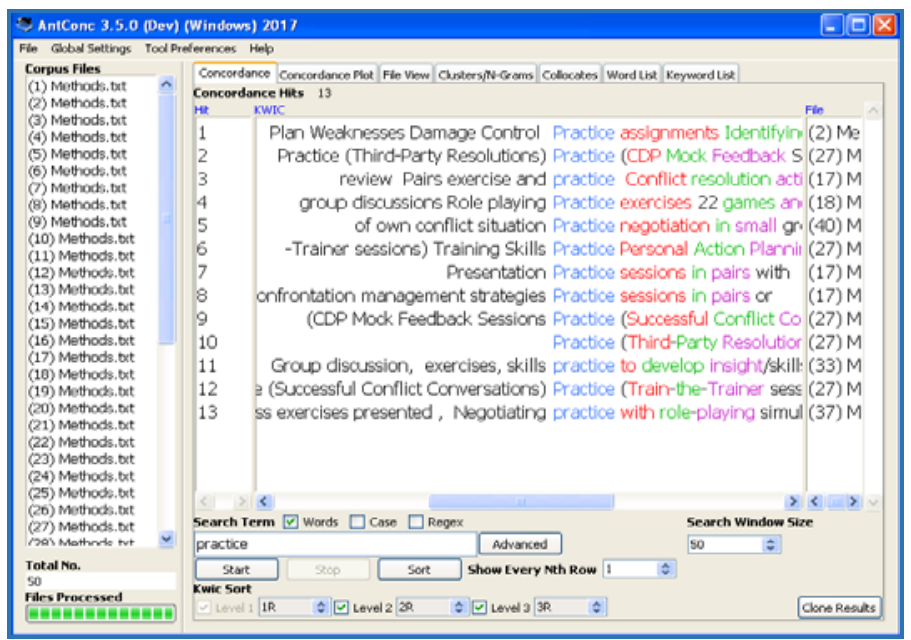

Figure 5. Practice, as teaching method in Conflict and Crisis management courses and trainings

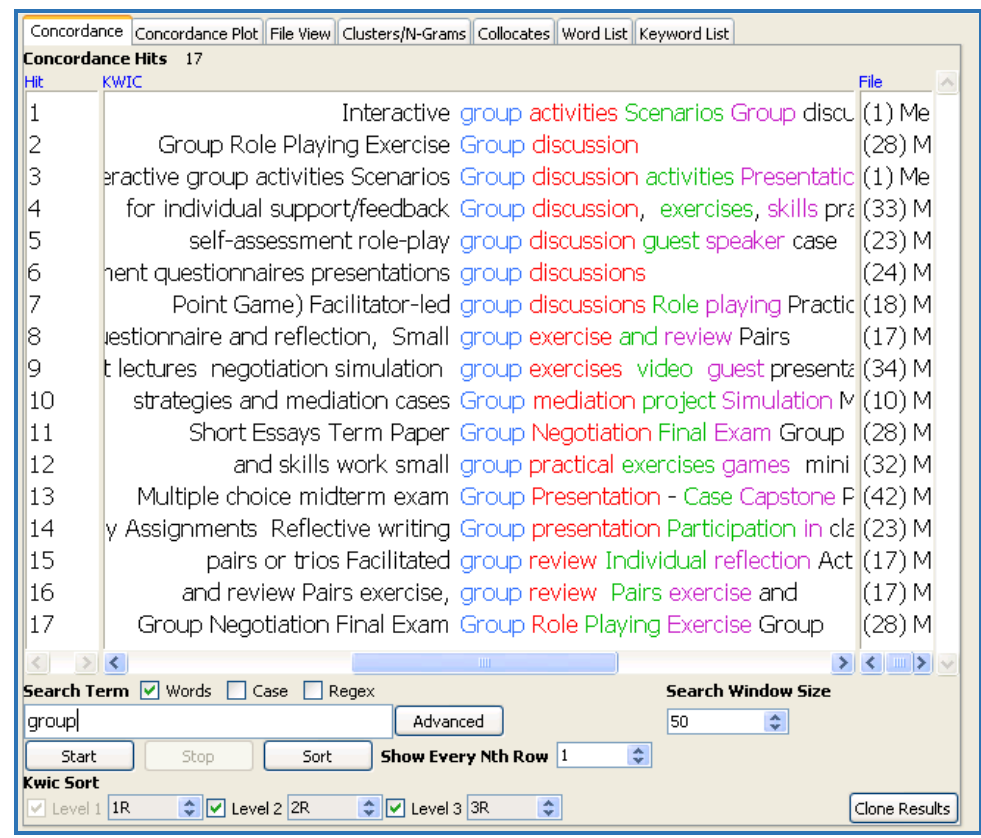

Figure 6 The group activities in Conflict and Crisis management courses and trainings

The results of corpus-based analysis have allowed stating the following recommendations on the design of courses in interpersonal skills:

- The actual practices in designing courses in interpersonal skills and the ways these courses are integrated into curricula didn't lead to good results up to now. The proof for this strong statement is the competences gap that continuously increases on the labor market. For this reason, the first recommendation is to change the actual curricular design practices.

- Especially in technical-oriented domains, such as informatics, it is a high need for the inclusion of more courses and extra-curricular activities related to interpersonal skills. Enforcement of teamwork skills by working in technical projects or improving the communications skills by learning how to write good project reports or scientific papers can't replace dedicated courses in teamwork and communication. Teaching effectively interpersonal skills requires much more time and adequate teacher expertise, in order to adequately address the physiological foundation of communication and self-management skills. 


\section{Issues in Information Systems}

Volume 21, Issue 4, pp. 178-186, 2020

- Communication is the most important interpersonal skill and should be addressed accordingly. The corpus based analysis results have showed that communication is present in the content of almost every course and training in interpersonal skills, But communication skills is not a technical or reporting-related issue.

- Interpersonal skills are interrelated and they can be associated into one single subject/course only if they are properly combined. For example, the corpus based analysis results have revealed that communication is strongly related with conflict management and not with teamwork (IT Curriculum combine communication with teamwork into one single subject).

- Self-assessment and other reflexive activities, together with workshops and other group activities are the most important teaching methods in interpersonal skills and it is recommended to use them more often.

- Investing in teachers and teaching in order to improve the delivery of all education activities, including those related to the improvement of interpersonal skills.

- Increase the awareness and the responsibility of teachers with technical background, who coordinate the technical projects or research related disciplines about/on the importance of interpersonal skills for the graduates' employment. All teachers should feel responsible for the development of interpersonal skills of the graduates.

- Increasing the interactivity and active participation of the students in all activities will lead to the improvement of graduates' interpersonal skills.

\section{SUMMARY}

The research reveals several solutions for the Improvement of the design of courses in interpersonal skills. There are many possible actions to be taken in this regards. The research has several limitations, mainly due to the complexity of curriculum design. These limitations are:

- Theoretical background of curriculum design was not fully considered.

- Not all the design levels were addressed.

- Quality assurance, including the educational programmes accreditation was not addressed and discussed.

- The corpus-based analysis was limited only to the current applied practices in courses and trainings.

One important way of action for is consider innovative approaches for strengthening the communication between education institutions and companies. In the seminal work, entitled "Beyond the Skills Gap: Preparing College Students for Life and Work", Hora, Benbow and Oleson (2016) present multiple opportunities for partnerships between higher education institutions and the relevant stakeholders connected with the labor market, as a complex framework for enhancing the graduates’ employability and interpersonal skills development.

The recent debates on the subject of interpersonal skills development have proposed the replacement of skills gap paradigm with shared commitment to education, workplace training and creation of high quality jobs. Assuring the graduate employability requires a strong (and strengthened) dialogue and communication between the higher education institutions and their staff and labor market actors, employers and other social partners. On one hand, the higher education institutions have to respond to labor market needs, but on the other hand companies have to understand the mission of higher education, which is to prepare students with a solid educational background for long-term and not just for immediate business needs. There are various ways of collaboration between higher education institutions and employers, e.g. through the careers services of the universities (which should have a proactive approach towards supporting the recruiting strategies of companies), through on campus job fairs and workshops, through internships and mentoring students.

\section{ACKNOWLEDGEMENT}

This paper is based on my thesis Methodological Contributions to Standard-based Curriculum Design, as a Means of Enhancing the Graduates' Employability done in June 2018 at The Bucharest University of Economic Studies under the supervision of Professor Laura Muresan, PhD. I would like to thank Professor Laura Muresan, $\mathrm{PhD}$ from The Bucharest University of Economic Studies of for her guidance. 


\section{REFERENCES}

ACM-IEEE Joint Task Group (2016a). Computer Engineering Curricula 2016 Curriculum Guidelines for Undergraduate Degree Programs in Computer Engineering, ACM and IEEE.

ACM-IEEE Joint Task Group (2016b). Information Technology Curricula 2017; Curriculum Guidelines for Baccalaureate Degree Programs in Information Technology, ACM and IEEE

Anthony, L (2004). AntConc: A Learner and Classroom Friendly, Multi-Platform Corpus Analysis Toolkit, An Interactive Workshop on Language e-Learning, IWLeL.

Anthony, L. (2005). AntConc: Design and Development of a Freeware Corpus Analysis Toolkit for the Technical Writing Classroom, IEEE International Professional Communication Conference Proceedings, 0-7803-9028$8 / 05 / \$ 20.00$

Beaumont, E., Gedye, S. \& Richardson, S. (2016). 'Am I employable?’ Understanding students' employability confidence and their perceived barriers to gaining employment, Journal of Hospitality, Leisure, Sport \& Tourism Education, issue 19.

Bodea, C.N. (2018). Methodological Contributions to Standard-based Curriculum Design, as a Means of Enhancing the Graduates' Employability, Dissertation, The Bucharest University of Economic Studies, Romania)

Hora, M.T., Benbow, R.J., Oleson, A.K. (2016). Beyond the Skills Gap: Preparing College Students for Life and Work, Harvard Education Press.

Muresan, L. (2017). Scientific communication in the age of globalisation: genre- and corpus-based approaches to research, Lecture notes, EDU-RES master degree programme, The Bucharest University of Economic Studies.

Pinto, L.H. \& Ramalheira, D.C. (2017). Perceived employability of business graduates: The effect of academic performance and extracurricular activities, Journal of Vocational Behavior 99 (2017) 165-178.

Popescu, M.E. \& Roman, M. (2018). Vocational training and employability: Evaluation evidence from Romania, Evaluation and Program Planning, 67 (2018) 38-46.

Topi, H., Valacich, J.S., Wright, R.T., Kaiser, K., Nunamaker, J.F. Jr., Sipior, J.C. \& de Vreede, GJ (2010). Curriculum Degree Programs Guidelines for Undergraduate in Information Systems, Association for Computing Machinery (ACM) and Association for Information Systems (AIS), available at: https://www.acm.org/binaries/content/assets/education/curricula-recommendations/is-2010-acm-final.pdf

Training Agency (1990). Enterprise in Higher Education: key features of Enterprise in Higher Education proposals, Training Agency, Sheffield. 